\title{
BENJAMIN E MARCUSE: DUAS LEITURAS CRÍTICAS DA REPRESSÃO DO EROS NA CIVILIZAÇÃO
}

\author{
Wilhelm Gustav Sousa Steinmüller
}

\begin{abstract}
RESUMO
Esta investigação visa reunir as abordagens da repressão do Eros na civilização enquanto componente da dimensão estética exposta por meio de uma leitura social e filosófica principalmente de Eros \& Civilização, de Herbert Marcuse, e Experiência e Pobreza, de Walter Benjamin, como obras principais, reflexão que não exclui a citação de outros ensaios dos autores.
\end{abstract}

Palavras-Chaves: Eros. Experiência. Pobreza. Benjamin. Marcuse

\section{BENJAMIN AND MARCUSE: TWO CRITICAL READINGS OF THE REPRESSION OF EROS IN CIVILIZATION}

\begin{abstract}
This research aims to collect the approaches of the Eros's repression at the civilization as na component of the esthetic dimension through a social and philosophic lecture, mainly of "Eros and civilization", by Herbert Marcuse, and "Experience and poverty", by Walter Benjamin as main literary works, reflection that doesn't exclude the possibility of references from other Works made by the authors.
\end{abstract}

Keywords: Eros. Experience. Poverty. Benjamin. Marcuse 


\section{Introdução}

\section{A repressão do Eros na sociedade}

Ao abordarmos o pensamento de Walter Benjamin, levamos em conta que seu método filosófico já refletia aquilo acerca do que escrevia: não há uma sofisticação das palavras neste filósofo, sua linguagem emprega o uso de palavras incomuns à tradição filosófica mas nem por isso com menos significado ou de menor importância para nosso problema.

Em seus escritos, Benjamin critica a verdade filosófica emaranhada em suas formas conceituais e herméticas, ao apontar para uma filosofia degenerada em sistema, em mito. Deste modo, Benjamin não se relaciona com a forma utilizada pela filosofia de seu tempo e busca retratar uma verdade que vai para além da palavra, embora nela situada e a ela limitada. É aquilo a que ele se refere como sendo, em seu escrito Sobre a linguagem geral e a sobre a linguagem do homem, ao tratar da linguagem enquanto "princípio que se volta para a comunicação de conteúdos espirituais" (BENJAMIN, 2013, 50). Neste sentido, a essência linguística está menos no comunicar as coisas do que "no fato de ele nomear as coisas" (Idem, 2013, 55). Esta é a distinção entre conteúdo manifesto ou conteúdo latente, entre significante e significado, bem como é propriamente o trabalho psicanalítico proposto por Lacan sob a tese de que "nenhum texto é o texto originário, de sentido puro" (BENJAMIN, 1976, 34). Benjamin antecipa esta avaliação ao expor que "no interior de toda configuração linguística reina o conflito do expresso e do exprimível com o inexprimível e o inexpresso" (BENJAMIN, 2013, 59). Isto deixa claro que Benjamin se expressa em um sentido mediado pela palavra, pelo qual é limitado, mas buscando "traduzir aquilo que não tem nome em nome" (BENJAMIN, 2013, 64).

Em $A$ vida dos estudantes, Benjamin tece uma crítica legítima frente a uma crise de significação histórica que ele percebe no estudantado alemão. Para expor este problema, o filósofo contrapõe a vida estudantil à ciência (BENJAMIN, 1986, 151) ou, ainda, à noção caótica que este estudantado carregava acerca do conceito de ciência. Para Benjamin, a ciência é tomada como sendo o "baluarte dos estudantes contra reivindicações 'estranhas'”(BENJAMIN, 1986, 
152). Aqui, a ciência é vista por Benjamin como um sistema profissionalizante que, levando-se em consideração as alternativas oferecidas pelo filósofo para uma "autêntica forma de vida para o ser humano", não leva em consideração qualquer totalidade dos indivíduos, mas sim "algo completamente fragmentário e postiço" (BENJAMIN, 1986, 153). Deste modo, Benjamin expõe sua crítica aos procedimentos no interior da instituição universitária, onde trabalho social e trabalho estudantil são desvinculados, constituindo, igualmente, "um conceito de dever desvinculado do seu trabalho pessoal e específico" (BENJAMIN, 1986, 153).

Para Benjamin, a escolha feita pelos estudantes de evitar, na juventude, o compromisso da solidão e da entrega, por medo, e desviar-se de ambos os pólos da vida (trabalho e família), são as causas do que ele expõe como uma "falta de compromisso erótico dos estudantes" (BENJAMIN, 1986, 158). Diz Benjamin:

Já que se vendeu a alma à burguesia, inclusive profissão e casamento, todo o mundo se agarra freneticamente àqueles poucos anos de liberdades burguesas. A troca se faz em nome da juventude. (BENJAMIN, 1986, 158)

Esta é uma crítica contra a ciência em seus métodos que defendem um discurso no qual o estudante não deva se preocupar tanto com os problemas de ordem social e suas práticas, mas sim com os problemas da vida intelectual e com o aparato profissionalizante enquanto o know how a ser absorvido. Entre os problemas decorrentes desta instrumentalização do saber, Benjamin expõe as infelizes consequências deste fenômeno, como por exemplo: a reação mecânica dos estudantes frente a esta "exposição do saber"; sua passividade; seu linguajar sofístico; a atrofia da criatividade em favor de hábitos estritamente acadêmicos. Em suas palavras, Benjamin aponta que:

Não raramente a comunidade social é o lugar onde se luta, sorrateiramente e em cumplicidade com outros, contra desejos mais elevados e metas próprias, e onde o desenvolvimento genuíno e mais profundo é encoberto. Na maioria dos casos, o desempenho social do homem comum serve para recalcar as aspirações originais e autênticas do homem interior. (BENJAMIN, 1966, 153) 
Em nossa análise, o contraponto à leitura da repressão da dimensão criativa e do Eros em Benjamin está na leitura de Herbert Marcuse. Na sua obra, Eros \& Civilização, Marcuse interpreta filosoficamente o pensamento de Freud. O encontro de Marcuse com o pensamento de Benjamin está, na perspectiva aqui contemplada, expressa no aspecto repressivo da civilização ao Eros bem como o Eros em seu aspecto repressivo e conformista. Ambos os autores, portanto, coadunam com a perspectiva da presença repressiva do Eros na civilização.

Para Marcuse, não se trata mais de uma sociedade desacelerada onde os processos psíquicos seriam "autônomos e identificáveis" (MARCUSE, 2015, 25), mas de uma sociedade em que estes mesmos processos estão sendo absorvidos pela função do indivíduo no estado, pelo seu papel político na dimensão que ocupa socialmente: no trabalho. Trata-se de uma perspectiva de uma sociedade industrial avançada que toma em consideração seu aspecto tecnológico e o utiliza não apenas no sentido de novas máquinas, mas também - senão principalmente - de novos procedimentos de controle e repressão das forças vitais, estas aqui significadas por meio do conceito de Eros. A técnica amplia uma disputa territorial da dominação, não se limitando exclusivamente ao seu aspecto físico, palpável, à propriedade, ao que é exterior ao indivíduo, mas envolvendo também categorias internas, psicológicas e metafísicas, o próprio terreno da subjetividade, uma transformação de valores e até mesmo da ideia de liberdade. Sobre isto, Marcuse observa:

Sob o domínio de um todo repressivo, a liberdade pode ser transformada em um poderoso instrumento de dominação. O leque de opções aberto ao indivíduo não é o fator decisivo na determinação do grau de liberdade humana, mas o que pode ser escolhido e o que é realmente escolhido pelo indivíduo. (MARCUSE, 2015, 46)

Esta transformação de valores foi descrita por Freud como sendo "a transformação do princípio de prazer em princípio de realidade" (MARCUSE, 2013. 34). Este é o mesmo processo que contrapõe o caos cultural (ADORNO, $1985,113)$ à "fantasia, que está 'protegida das alterações culturais' e mantémse vinculada ao princípio de prazer" (MARCUSE, 2013, 35). Deste modo, o processo de instrumentalização e do espírito profissional, representado na figura 
de Thanatos, funciona como força repressora e dominadora em seu embate contra Eros, que em seu significado representa a fantasia do espírito criador. Tal uniformização pode, assim, ser percebida tanto na dinâmica presente no interior da academia, como posto por Benjamin, quanto do seu lado exterior, na vida profissional; tanto na vida psíquica quanto na vida social; tanto na família quanto na política ou no trabalho; tanto na libido quanto na cultura sob a "disseminação de bens padronizados para a satisfação de necessidades iguais" (ADORNO, 1986, 114).

É diante do que até aqui foi exposto que situamos o cerne do nosso problema: nas relações entre as perspectivas de Marcuse e Benjamin sobre 0 contraste entre as demandas sociais e a vida particular, entre as repressões exteriores e a liberdade interior, entre Thanatos e Eros, entre o espírito conformista e o espírito criativo, a informação e a narrativa, a razão e a fantasia, entre o pensamento analítico e a literatura alegórica, enfim, entre contrastes de um mesmo ser que não poderia se unidimensionar ou transitar por uma via de mão única sem sérias consequências para sua vida, suas experiências e sua estrutura psíquica. É também uma perspectiva que visa não simplesmente dissolver as fronteiras erigidas pelo conhecimento analítico ou puramente conceitual, hermético, mas sim e principalmente, unir o potencial criativo e as forças anti-alienantes, lúdicas e livres à própria construção do conhecimento como tal.

\section{Formas de dominação e repressão do Eros na sociedade}

Em Eros \& Civilização, Marcuse expõe a origem da civilização repressiva sob a justificação de evitar a situação onde cada um quer todo o prazer para si. Isto funda a necessidade de uma ordem a ser respeitada por todos a fim de que se possa conviver em sociedade, ordem esta que vem sob a forma de repressão, de leis, de costumes, de um adestramento. Trata-se de promover o controle do prazer, traçando um limite da satisfação a que cada um deva se resignar, na intenção de controlar os impulsos destrutivos do Eros e expandindo o "progresso da dominação" (MARCUSE, 1978, 73). Nesta mesma análise, Marcuse aponta para o que Freud indicou como sendo um "período de matriarcado" (MARCUSE, 1978, 73), marcado pela formação de unidades mais vastas sob o signo da 
sexualidade organizada e marcado por uma maior liberdade erótica e baixo grau de dominação repressiva e representativo da função do Eros na civilização.

Em O homem unidimensional, somos advertidos por Marcuse acerca da perspicácia na qual "a dominação de Eros é, desde o início, também de Thanatos" (MARCUSE, 2015, 101). Ao apontar o "contraste entre a representação da sexualidade nas literaturas clássicas e romântica e em nossa literatura contemporânea" (MARCUSE, 2015, 101), Marcuse revela que a dominação tem alcançado sucesso até mesmo sob certas manifestações do Eros, que passa a exercer, assim como Thanatos, uma força repressiva sob o indivíduo. Muito embora Marcuse aponte que, para Freud, "o princípio de prazer e o princípio de realidade são 'eternamente' antagônicos” (MARCUSE, 1978, 37), o filósofo acrescenta sua perspectiva do Eros sob a influência da sociedade industrial avançada. Marcuse acrescenta que:

(...) a sexualidade torna-se um veículo para os best-sellers da opressão. (...) Essa sociedade transforma tudo o que toca em uma fonte potencial de progresso e exploração, de escravidão e satisfação, de liberdade e de opressão. (MARCUSE, 2015, 102).

Deste modo, Marcuse deixa claro que uma maior liberdade sexual não representa uma maior liberdade erótica, ao mesmo tempo em que revela que o aspecto conformista pode estar presente até mesmo nos traços característicos do Eros sob forma de dominação e/ou alienação. Deste modo, até mesmo os próprios desejos do sujeito deixam de pertencer-lhe sob a economia do princípio de realidade, passando estes desejos, então, "a ser 'organizados' pela sociedade" (MARCUSE, 1978, 36). Vale salientar nesta reflexão, que esta perspectiva aborda apenas uma das facetas da dimensão criativa, do Eros, mais precisamente seu aspecto libidinal, embora levando em conta que a dimensão do Eros, na qual situamos a estética, envolve todo o aspecto criador e nãoconformista com o status quo vigente ou com a ordem das coisas estabelecidas.

Benjamin nos apresenta um outro tipo de convenção repressiva que se encaixa na nossa perspectiva crítica da repressão ao Eros na sociedade. Tal convenção, é percebida pelo filósofo como sendo uma espécie de "algema": trata-se da convenção da "ideia de casamento, de família" (BENJAMIN, 1986, 
156). Este outro pólo da existência humana, contraposto ao trabalho, nos é apresentado sob a forma da convenção familiar, convenção esta que exerce peso sobre o Eros dos criadores. Esta cisão entre particular e público é resgatada pelo pensador como estando presente tanto na sociedade clássica grega - na forma da submissão do "Eros procriador ao eros criador" (BENJAMIN, 1986, 157); quanto entre os cristãos, enquanto rejeitando tanto a individualidade do trabalho quanto a do Eros. Ao estudantado, a crítica se volta contra suas "considerações infinitamente estetizantes" do Eros que refletem uma neutralização erótica do alunado. Ao citar a queda do matriarcado e sua substituição "por uma contra-revolução patriarcal" (MARCUSE, 1978, 73), Marcuse insere a participação da religião institucionalizada enquanto força estabilizadora deste mesmo patriarcado. Desta forma, se impõem sob o Eros criador, dois pesos de dois medos distintos: o da burguesia, que neutraliza seu potencial criativo; e o da Igreja católica, que teme o "poder e a necessidade do Eros" BENJAMIN, 1986, 157).

Em suma, as formas de se neutralizar o importante papel do Eros enquanto dimensão criativa estão presentes em ambos ambientes de desenvolvimento, seja particular, seja social; e em ambas as críticas, tanto em Marcuse quanto em Benjamin.

\section{As saídas da repressão: a nova barbárie da dimensão estética}

Mas sempre existiram as forças de resistência, Marcuse aponta: "as pervesões revelam uma profunda afinidade com a fantasia como sendo aquela atividade mental que 'foi conservada imune ao teste da realidade e permaneceu exclusivamente subordinada ao princípio de prazer"' (MARCUSE, 1978, 62).

"A tarefa cultural (a tarefa vital?) da libido - ou seja, tornar 'inofensivo o instinto destrutivo' - fica reduzida a zero" (MARCUSE, 1978, 62).

A gíria e a fala coloquial raramente foram tão criativas. É como se o homem comum (ou seu porta-voz anônimo) afirmasse em sua fala sua humanidade contra os poderes existentes, como se a rejeição e a revolta, subjugadas na esfera política, explodissem no vocabulário que chamam as coisas pelos seus nomes. (MARCUSE, 2015, 109) 
Tanto em Walter Benjamin quanto em Herbert Marcuse estão presentes a aceitação de uma sociedade com pretensões totalitárias, tanto no que toca a dimensão do trabalho quanto a dimensão do Eros. Este é o reflexo, para Marcuse, de uma sociedade onde predomina "o domínio do homem pelo homem" (MARCUSE, 1978, 27) sob tutela da razão instrumental, cientificista e unidimensional. Neste ponto propõe-se a apresentação de Marcuse acerca da noção de civilização não-repressiva, rejeitando a identificação de Freud da civilização com a repressão, "examinada não como uma especulação abstrata e utópica"1, mas justificada em dois dados concretos e realistas:

\begin{abstract}
A própria concepção teórica de Freud parece refutar a sua firme negação da possibilidade histórica de uma civilização não-repressiva; e, segundo, as próprias realizações da civilização repressiva parecem criar as precondições para a gradual abolição da repressão (MARCUSE, 1978, 28).
\end{abstract}

Na leitura de Marcuse, "a teoria de Freud é, em sua própria substância, 'sociológica'” (MARUSE, 1978, 29). Isto significa que Marcuse toma as hipóteses operacionais construídas por Freud como axiomas para sua leitura sociológica de sua psicanálise, questionando a impossível conciliação entre duas dimensões constitutivas do ser humano: o princípio de prazer e o princípio de realidade materializado num sistema de instituições. Vale levar em consideração que em Marcuse as categorias psicológicas de Freud são convertidas em categorias políticas Aqui está em foco a dinâmica entre a existência biológica e a existência social; entre o id e o ego. Para tanto, Marcuse indica algumas transformações "no sistema dominante de valores" (MARCUSE, 1978, 34) enquanto substituição do princípio de prazer pelo princípio de realidade (enquanto valores antagônicos): de uma satisfação imediata para uma satisfação adiada [controle]; do prazer para a restrição do prazer [estética]; do júbilo (atividade lúdica) para o esforço (trabalho) [capital]; da receptividade para a produtividade; da ausência de repressão para a segurança [medo]. Tais modificações expõem, em Marcuse, os frutos do caráter repressivo da sociedade que revela sua estrutura racional

\footnotetext{
${ }^{1}$ Apesar da utopia ser uma marca percebida, em Marcuse, (MARCUSE, 1978, 34) por parte de seus leitores.
} 
estruturada em prol do fator econômico ao afirmar que "a cultura não é refutada: escravidão e coação representam o preço que deve ser pago (MARCUSE, 1978, 38).

Expostas ambas perspectivas, tanto para Marcuse quanto para Benjamin, a situação de repressão do Eros criativo e criador - este que se encontra domínio do princípio de prazer - revela "uma vida que precisa da arte" (BENJAMIN, 1986, 155). É por meio da idealização, da fantasia e da imaginação que o papel estético desepenhado pelo artista encontra, em Marcuse, reflete uma consciência capaz de uma dupla alienação capaz de superar a repressão ao Eros conforme aqui está exposta. Trata-se de uma alienação do artista em relação a sua realidade bem como sua capacidade de entreter uma forma ideal de vida enquanto situado em situações menos que ideais. Esta dupla alienação do artista é tomada por Marcuse como sendo o elemento catalisador da mudança social, que indica o potencial para libertação e auxiliador na formação daquilo que ele toma como uma subjetividade radical.

Em Benjamin, foi "por falta de coragem" (BENJAMIN, 1986, 159) que a vida dos estudantes se afastou do tipo de conhecimento presente na "amizade expensiva dos criadores, voltada ao infinito e sempre dirigida à humanidade" (BENJAMIN, 1986, 158).

\begin{abstract}
Ora, toda forma de vida e seu ritmo emanam dos mandamentos que determinam a vida dos criadores. Enquanto se esquivarem disso, sua existência os punirá com realdade, e o desespero golpeará mesmo o coração do embotado (BENJAMIN, 1986, 159).
\end{abstract}

Marcuse situa-se a favor de Brecht e contra a tirania da forma, ao afirmar que não é a arte que se submete à forma, mas sim que é "a forma que se submete" (MARCUSE, 1986, 52) à arte.

"A análise da função cognitiva da fantasia conduz-nos assim à estética como "ciência da beleza": subentendida na forma estética situa-se a harmonia reprimida do sensualismo e da razão - o eterno protesto contra a organização da vida pela lógica da dominação, a crítica do princípio de desempenho. 
Por fim, é possível perceber um consenso, tanto em Benjamin quanto em Marcuse, de que a dimensão estética preserva um importante papel diante dos procedimentos operacionais, herméticos, repressivos e limitantes da sociedade. $\mathrm{Na}$ figura do Eros é que está situado o caráter emancipatório da arte e a retomada da subjetividade crítica que nega a realidade estabelecida, uma vez que: permite construir valores e ideais que abrem espaço para pensar uma revolução possível; possibilita - por meio da fantasia da subjetividade radical do artista - formas ideais de vida; e, não menos importante, apresentam desafios reais à ordem social estabelecida, ao status quo vigente.

Em última instância, contraponto à crítica de Benjamin está na leitura de Marcuse. Marcuse afirma uma verdade na autonomia da arte, onde situa sua essência, "na qual reside a verdade da arte e que determina o valor político da arte" (MARCUSE, 1986, 59). Ele também indica que, se a arte por si mesma não trouxer à tona a libertação, o papel da arte deve ser traduzido em atividade política. Aqui, estética e política, qualidade e tendência estão intimamente relacionados tanto em Marcuse quanto em Benjamin, muito embora Marcuse aponte em Benjamin uma "identificação da qualidade literária e política no domínio da arte" (MARCUSE, 1986, 60) quando cita que:

\footnotetext{
Walter Benjamin formulou a relação interna entre tendência e qualidade na tese: 'A tendência da obra literária só pode ser politicamente correcta se também for correcta pelos padrões literários"'. (MARCUSE, 1986, 60)
}

Marcuse afirma que esta identificação pode realizar uma harmonia naquilo que naturalmente se mostra como uma "tensão entre forma literária e conteúdo político", e acrescenta, por fim, que "a forma literária perfeita transcende a tendência política correta; a unidade da tendência e da qualidade é antagônica" (MARCUSE, 1978, 60).

\section{REFERÊNCIAS}

BENJAMIN, Walter. A vida dos estudantes. In: Documentos de cultura, documentos de barbárie: escritos escolhidos / seleção e apresentação Willi Bolle; trad. Celeste H. M. ribeiro de Sousa / et al./ - São Paulo: Cultrix Editora da Universidade de São Paulo. 1986. 
. Escritos sobre mito e linguagem. Tradução de Suzana Kampff Lages e Ernani Chaves. São Paulo, SP: Editora 34, 2013.

. Experiência e Pobreza. In. Magia e técnica, arte e política: ensaios sobre literatura e história da cultura. Tradução Sérgio Paulo Rouanet. 7. ed. São Paulo: Brasiliense, 1994.

O narrador. In. Magia e técnica, arte e política: ensaios sobre literatura e história da cultura. Tradução Sérgio Paulo Rouanet. 7. ed. São Paulo: Brasiliense, 1994.

KOTHE, Flávio. Para ler Benjamin. Editora Francisco Alves, 1976.

MARCUSE, Herbert. A Dimensão Estética. Tradução de Maria Elisabete Costa. Lisboa, Portugal: Edições 70, 1986.

Eros e Civilização: uma interpretação filosófica do pensamento de Freud. 8a. ed. Tradução de Álvaro Cabral. Rio de Janeiro: Zahar editores, 1978.

. O homem unidimensional: estudos da ideologia da sociedade industrial avançada. Tradução de Robespierre de Oliveira, Deborah Christina Antunes e Rafael Cordeiro Silva. São Paulo: EDIPRO, 2015.

OLIVEIRA, Robespierre. As afinidades eletivas: Marcuse e Benjamin. Palestra proferida no III Seminario Internacional Políticas de la Memoria Recordando a Walter Benjamin: Justicia, Historia y Verdad. Escrituras de la Memoria. Buenos Aires. 2010. Disponível em 24 de agosto de 2015. <http://conti.derhuman.jus.gov.ar/2010/10/mesa-34/oliveira_mesa_34.pdf>. 